\title{
Reaching the poor through community-based distributors of contraceptives: experiences from Muheza district, Tanzania
}

\author{
DAUDI SIMBA $^{1 *}$, CORDULA SCHUEMER ${ }^{2}$, KATE FORRESTER ${ }^{3}$ and MERRIMENT HIZA ${ }^{2}$ \\ ${ }^{1}$ Department of Community Health, Muhimbili University of Health and Allied Sciences, P.O. Box 65015, \\ Dar es Salaam. Tanzania \\ ${ }^{2}$ Tanzania German Programme to Support Health, P.O. Box 5187, Tanga, Tanzania \\ ${ }^{3}$ P.O. Box 801, Iringa, Tanzania
}

\begin{abstract}
Community based distribution (CBD) programmes were introduced as a strategy to ensure access of contraceptives to the needy. The strategy is reported to increase contraceptive knowledge and use. Although CBD agents have the advantage of reaching the poor in rural areas, wealth gap does exist even in these settings. The objective of this study was to determine access to information and modern contraceptives services among people of different wealth status in a rural setting in Muheza, Tanzania. This cross-sectional study was conducted following a six year project in promotion of contraceptive using community-based agents. The study area was stratified into three socio-geographical strata from which one village was randomly selected. Through house-tohouse visits, interviews were conducted using structured questionnaires until the required sample size was obtained. A community-led wealth ranking criteria was developed through consensus and used to classify respondents into wealth categories. A total of 1,420 respondents were interviewed. Contraceptive Prevalence Rate (CPR) for modern methods was $32.2 \%$; injectables accounted for half $(50.8 \%)$ followed by pills $(32.7 \%)$. CBD agents accounted for one-third $(34.3 \%)$ of the contraceptive use. There was no difference in the access to information $(P=0.44)$ and to contraceptives $(P=0.83)$ between the poorer and the less poor. Half of the respondents $(49.4 \% ; 214 / 431)$ reported paying for services, with no difference between the less poor and the poorer $(P=0.75)$. Respondents receiving services from health facilities were more likely to pay for services $(61.3 \%)$ compared to CBD agents $(25.0 \%)$. However, the level of satisfaction was high (approximately $70 \%$ ) in both health facilities and CBD agents. This study has shown that people in the rural settings of Muheza district were able to access information and contraceptives from CBD agents and health facilities, regardless of their wealth status. There is however, need to address the issue of informal payments lest it deters people in need from accessing the services.
\end{abstract}

Key words: Community-based distribution agents, poverty, contraceptives, Tanzania

\section{Introduction}

The level of contraceptive use is a factor of availability and accessibility of family planning (FP) services. Bertrand (1995) defines accessibility to family planning services as the extent to which services are available and can be obtained by those seeking the services. The term accessibility includes physical proximity, travel time, economic, psychological, attitudinal, cognition and perception of the potential clients of the respective service (Thang \& Anh, 2002). Various strategies have been employed to ensure access of contraceptives to the needy. This is on the understanding that poverty and high fertility forms a vicious cycle, thus, addressing access to contraceptive is one way of addressing the challenges for attaining the first Millennium Development Goal that is, poverty alleviation.

\footnotetext{
*Correspondence: Dr. Daudi Simba; E-mail: dsimba@muhas.ac.tz; daudisimba@yahoo.com
} 
Community based distribution (CBD) is one of the most effective strategy for increasing contraceptive use (Jahanfar et al., 2005). CBD is a strategy for provision of family planning services using community structures that includes home visiting by trained agents with the aim of promoting the use of safe contraceptive methods (Routh et al., 1997). CBD programmes were introduced with a view to reaching populations with inadequate health facility based distribution, hence, limited access to family planning services (Jahanfar et al., 2005; Prata et al., 2005). CBD agents have been reported to increase modern contraceptive use by 3 to 10 times (Routh et al., 2001).

Inequity in accessing family planning methods has ethical implications. This is because lack of access to information and services among the poor undermines their ability to prevent high risk births (Gillepsie et al., 2007). Effective family planning (FP) programmes have been reported to reduce the fertility differential between the wealthiest and the poorest thus contributing to poverty reduction (Shah \& Chandra-Mouli, 2007). It has been argued all along that, CBD agents have the advantage of reaching the majority of the people living in rural areas (Prata et al., 2005). However, wealth gap exists even in rural settings; although, the range is narrow (Gillepsie et al., 2007; Jacobs \& Price, 2005). Understanding the dynamics and contextual factors involved in the disparity might enable programmes to design effective interventions (Shah \& Chandra-Mouli, 2007). Many studies have been done focusing on implementation of CBD programmes, but, inequity in accessing family planning services has received scant attention (Gillepsie et al., 2007). The few studies conducted have indicated lower contraceptive use among the poorer relative to wealthier populations (Gillepsie et al., 2007; TDHS, 2005).

In Tanzania, the first CBD programme in Tanzania started in 1988 through the Family Planning Association of Tanzania (Janowitz et al., 2000). However, many other programmes started in the 1990s and by 1996 CBD programmes were in existence in $20 \%$ of the districts in the country (Janowitz et al., 2000). This study is based on a Community Based Distribution programme that has been operating in Muheza, Tanzania using volunteers at village level since 2001. The programme has been run by the district council health management team with support from the Tanzania German Programme to Support Health (TGPSH/GTZ). In this district, CBD agents were responsible for distributing condoms and oral contraceptives under the supervision of health workers from the nearest health facility. In addition to addressing sensitive issues and initiating discussion on family planning among couples, CBD agents also referred clients to health services for other reproductive health services such as treatment of sexually transmitted infection, voluntary counselling and testing, antenatal and delivery care. CBD agents normally perform their work through home visits, fixed and mobile CBD posts, one-to-one and group education meetings and provide contraceptive services free of charge. The objective of this study was therefore, to determine access to information and modern contraceptives services among people of different wealth status in a rural setting in Muheza, Tanzania.

\section{Materials and Methods}

\section{Study population and setting}

The study was conducted in Muheza district in north-eastern Tanzania in August 2005. According to the 2002 National Census, Muheza had an estimated population of 295,000 living in an area of $4,922 \mathrm{~m}^{2}$ (T. Jaenisch et al., unpubl.). The district was selected for the study since TGPSH has been working actively in the district to promote access of 
contraceptives through CBD agents for the past six years. The study was done in Maramba Division where there were 85,000 inhabitants living in 30 villages in 5 wards. Maramba Division was selected for the study because it had the highest numbers of active CBD agents and consisted of a variety of terrain with people engaged in different types of economic activities such as farming, livestock keeping and business. Baseline data conducted in 1999 reported contraceptive prevalence rate in Muheza district was 24\% (Jaenisch et al., 2001).

\section{Study design and sample size}

A cross-sectional descriptive study was conducted among people of reproductive age (1549 years) in three villages using a structured questionnaire. The sample size was calculated as 385 using 95\% confidence and that the proportion of people reported to use contraceptive methods was estimated at 40\% (Jaenisch et al., 2001) and the standard deviation was 1.96. In order to compensate for incomplete information or non-response, a safety margin of $25 \%$ was added. This increased the sample size to 462 . Using the lowest estimate of 33\% contraceptive prevalence rate found in 2001 in Muheza, calculations were made to determine the number of respondents required to obtain 462 contraceptive users. This was found to be 1,400 .

\section{Sample selection}

The study area was stratified into three socio-geographical strata from which one village was randomly selected to represent a particular terrain. Kidundui was selected to represent fertile mountainous areas with regular rainfall throughout the year; Mavovo represented plain arid dry land while Gombero represented coastal terrain that fell between that of Kidundui and Mavovo. The presence of active CBD agents in the villages was an important criterion to ensure that an adequate number of clients getting contraceptives from CBD agents were obtained to allow comparison with those getting them from health facilities. The study unit/subjects were individuals living in the three villages found at home at the time of the interview. These were obtained through random selection of the first house in a village, followed by the next house to the right until the required sample was attained.

\section{Data collection}

Community-led wealth ranking has been reported to be a feasible and effective way of identifying members of the community who are poorer in rural settings (Jacobs \& Price, 2005). In this study, a community-led wealth ranking was used to categorise people into three wealth ranks; the less poor, poor and poorer. First, the wealth categories were developed based on qualitative method using the CBD agents as key informants to come up with wealth criteria specific to their locality. CBD agents from one village were grouped together and with the support from a social scientist, CBD agents were asked to report the wealth rank of the households they served. CBD agents were then asked to mention what characterises a better-off person (less poor) from an average person and a poor person (poorer) from an average person, using the list of households by rank as a reference for their discussions, until they came to a consensus. The following characteristics were mentioned; land size (farmers), number of live-stock (for livestock keepers) type of business (for businessman) and occupation (if employed). The variables were then categorised into wealth levels as shown in Box 1. Since many people were found to have 
mixed occupations this necessitated development of a secondary criterion (overall criteria) that took into account all the occupational activities.

\section{Farmer}

Better off: Having 5 or more acres of land and (food sufficiency with at least one crop or having at least one cash crop)

Average: Having 2-4 acres of land and (food sufficiency with at least one crop or having at least one cash crop) or having one acre of land and (food sufficiency with at least one crop and having at least one cash crop)

Poor: Having one acre of land and food sufficiency but no cash crop or having one acre of land and at least one cash crop but no food sufficiency or having less than one acre of land

\section{Livestock}

Better off: Having 5 or more cows

Average: Having 1-4 cows or 5 or more goats or 50 or more chickens

Poor: Having less than 5 goats or having less than 50 chickens

\section{Business}

Better off: Own milling machine or shop or kiosk or buying and selling crops or buying and selling livestock or selling timber

Average: Own a café or stall or sells alcohol or makes and sell charcoal or sells cloth through vending or artisan (tailoring, masonry, radio repair)

Poor: Selling buns / bread or selling mangoes / oranges / groundnuts or selling coffee or selling mats or selling fish / barbeque or selling kerosene or photographer

\section{General status (Overall)}

Better off: Regular salary (not less than official minimum wage) or better off in farming or better off in livestock keeping or better off in business

Average: average in farming or average in livestock keeping or average in business

poor : poor in farming or poor in livestock keeping or poor in business

\section{Box 1: Criteria for wealth status for quantitative analysis}

A pre-tested questionnaire was used to collect data. Ten trained research assistants made house to house visits to interview members of household who reported to be within the age range of 15 to 49 years. Respondent were interviewed in a secluded place to ensure confidentiality. A verbal informed consent was obtained prior to the interviews. Using a questionnaire, information was sought on contraceptive use, source of information on contraceptives, socio-economic and wealth characteristics, whether they paid for the services or not and their level of satisfaction with the services received. The level of satisfaction was measured using a scale of three categories; high, moderate and low. At the end of each day, the questionnaires were checked for errors and incomplete filling. These were rectified and where not possible follow-up visits were made to inquire for the correct responses.

\section{Data analysis}

Data were entered and analysed using EPI-Info software version 6. Data validation was done by counterchecking for outliers and inconsistencies using frequency and two by two tables. Wealth rank was assigned to each respondent according to wealth characteristics reported and the categories made through the qualitative process. Comparison was made 
by wealth status on current use of modern contraceptive methods, source of contraceptives and source of information on contraception. Analysis was also performed on client satisfaction and reported payment by wealth status. Chi-square test was used to establish significant difference using p-value cut off point of 0.05 .

\section{Results}

A total of 1420 respondents were interviewed of which $64.2 \%$ were female. About half of the respondents had completed primary school education $(53.8 \%$ ) and almost a quarter of them (23.4\%) had not attended formal education. About $80 \%$ of the respondents reported small scale farming as their main occupation. The overall current contraceptives use for modern methods was 30.4 (males $=27 \%$; females $=32.2 \%$ ). The most favoured method was injectables that accounted for half $(50.8 \%)$ of all modern contraceptive use followed by pills $(32.7 \%)$. Condom use, as a method of contraception was the lowest $(13.7 \%)$. There was slightly higher use of contraceptives among the poorer (33.0\%) compared to the less poor $(31.7 \%)$. However, the difference was not statistically significant $(P>0.05)$ (Table 1$)$.

Table 1: Current contraceptive use for modern methods by wealth status and sex

\begin{tabular}{llllllllll}
\hline Wealth status & Male & \multicolumn{3}{c}{ Female } & \multicolumn{3}{c}{ Overall use } & Grand total \\
\cline { 2 - 10 } & No. & $\%$ & Total & No. & $\%$ & Total & No. & $\%$ & No. \\
\hline Less poor & 16 & 21.3 & 75 & 33 & 31.7 & 104 & 49 & 27.4 & 179 \\
Poor & 91 & 28.4 & 320 & 186 & 32.0 & 581 & 277 & 30.7 & 901 \\
Poorest & 30 & 26.5 & 113 & 75 & 33.0 & 227 & 105 & 30.9 & 340 \\
Total & 137 & 27.0 & 508 & 294 & 32.2 & 912 & 431 & 30.4 & 1420 \\
\hline
\end{tabular}

Pearson $\operatorname{chi}^{2}(2)=1.5700 \operatorname{Pr}=0.456$ (Males); Pearson $\operatorname{chi}^{2}(2)=0.0924 \operatorname{Pr}=0.955$ (Female)

Most of the respondents accessed contraceptives through health facilities (62.9\%) compared to CBD agents $(34.3 \%)$ (Table 2). There was no difference in the access to contraceptives between the poorer and the less poor from any of the two main sources. Similar findings were observed when analysis was done on wealth status by type of contraceptive. Clients from Mavovo village had significantly better access to contraceptives supplied by CBD agents (46.1\%) compared to Kidundui (27.9\%) and Gombero (30.2\%) $(P<0.05)$. There was, however, no difference in the source of contraceptive by wealth status in the three villages.

Respondents were asked to mention the source of information that led them to seek for the respective contraceptive method. Table 2 shows that majority $(68.1 \%)$ of the respondents received information from the health facilities. CBD agents were a source of information to about a quarter of the users (27.0\%). Analysis done on source of contraceptive information by wealth status revealed no significant difference between the less poor and the poorer ( $p$-value $>0.05$ ). Further analyses revealed that the majority of the respondents who sought services from the health facilities reported to have received initial information from health facility workers (86.6\%); and those reporting to obtain services from CBD agents got initial information from them $(90.4 \%)$. 
Table 2: Reported source of contraceptives and information by wealth status

\begin{tabular}{|c|c|c|c|c|c|c|c|c|c|}
\hline \multirow[t]{2}{*}{ Source of } & \multirow[t]{2}{*}{ Wealth status } & \multicolumn{2}{|c|}{ HFs } & \multicolumn{2}{|c|}{ CBD } & \multicolumn{2}{|c|}{ Others } & \multirow[t]{2}{*}{ Total } & \multirow[t]{2}{*}{ P-value } \\
\hline & & No. & $\%$ & No. & $\%$ & No. & $\%$ & & \\
\hline \multirow[t]{4}{*}{ Contraceptive } & Less poor & 30 & 61.2 & 17 & 34.7 & 2 & 4.1 & 49 & 0.83 \\
\hline & Poor & 178 & 64.3 & 93 & 33.6 & 6 & 2.2 & 277 & \\
\hline & Poorest & 63 & 60.0 & 38 & 36.2 & 4 & 3.8 & 105 & \\
\hline & Total & 271 & 62.9 & 148 & 34.3 & 12 & 2.8 & 431 & \\
\hline \multirow[t]{4}{*}{ Information } & Less poor & 29 & 59.2 & 18 & 36.7 & 2 & 4.1 & 49 & 0.44 \\
\hline & Poor & 194 & 70.3 & 70 & 25.4 & 12 & 4.3 & 276 & \\
\hline & Poorest & 70 & 66.7 & 28 & 26.7 & 7 & 6.6 & 105 & \\
\hline & Total & 293 & 68.1 & 116 & 27.0 & 21 & 4.9 & 430 & \\
\hline
\end{tabular}

About half of the contraceptive users (49.4\%) reported to have paid for the services (Table $3)$. There was no difference in the reported payment between the less poor and the poorer $(P>0.05)$. Further analysis of wealth status by source of contraceptives showed that respondents who received services from health facilities were more likely to report paying for the contraceptives $(61.3 \%)$ compared to those who received from the CBD agents $(25.0 \%)$.

Table 3: Paying for contraceptive services by wealth status and source

\begin{tabular}{llllllll}
\hline Variable & & Paid & $\mathbf{\%}$ & Not paid & $\mathbf{\%}$ & Total & P-value \\
\hline Wealth status & Less poor & 22 & 44.9 & 27 & 55.1 & 49 & 0.75 \\
& Poor & 140 & 50.5 & 137 & 49.5 & 277 & \\
& Poorest & 51 & 48.6 & 54 & 51.4 & 105 & \\
& Total & 213 & 49.4 & 218 & 50.6 & 431 & \\
\hline Source of & HFs & 166 & 61.3 & 105 & 38.7 & 271 & 0.00 \\
contraceptives & CBD & 37 & 25.0 & 111 & 75.0 & 148 & \\
& Others & 10 & 83.3 & 2 & 16.7 & 12 & \\
& Total & 213 & 49.4 & 218 & 50.6 & 431 & \\
\hline
\end{tabular}

About two-third of the respondents $(67.3 \%)$ reported to be highly satisfied with the services (Table 4). Although the poorer reported the lowest level of satisfaction $(62.9 \%)$ compared to the less poor $(71.4 \%)$ the difference was not statistically significant $(P>0.05)$. Majority of the people had high level of satisfaction for services offered from health facilities (67.2\%) as well as from the CBD agents (68.2\%).

Table 4: Level of satisfaction with family planning services by wealth status

\begin{tabular}{llllllll}
\hline Wealth status & Low & $\mathbf{\%}$ & Moderate & $\mathbf{\%}$ & High & $\mathbf{\%}$ & Total \\
\hline Less poor & 1 & 2.0 & 13 & 26.5 & 35 & 71.4 & 49 \\
Poor & 22 & 7.9 & 66 & 23.8 & 189 & 68.2 & 277 \\
Poorest & 10 & 9.5 & 29 & 27.6 & 66 & 62.9 & 105 \\
Total & 33 & 7.7 & 108 & 25.1 & 290 & 67.3 & 431 \\
\hline Pearson $\mathrm{Chi}^{2}(4)=3.4786$ & $\mathrm{Pr}=0.481$ & & & &
\end{tabular}

\section{Discussion}

In this study, a relatively high current contraceptive use for modern methods was found in Muheza, which was twice higher compared to the national figures for rural areas in Tanzania (TDHS, 2005). The study has also shown that people in these rural settings had 
access to information and use modern contraceptives regardless of their wealth status. Study based on demographic health surveys from 41 developing countries reported inequities in knowledge and fieldworkers' contact for modern contraceptive among countries in sub-Saharan Africa (Gillepsie et al., 2007). In Tanzania, reports showed that people in the less poor quintile accessed contraceptive services 3-times more than those in the poorer quintile (TDHS, 2005) and in most rural areas there were no CBD agents (TRCH, 1999). Thus, in the absence of alternative explanation, the high contraceptive use in the present study the lack of disparity between the less poor and the poorer might be attributed to the sustained successful effort by the CBD in Muheza district.

CBD agents are able to reach the poorer because they tend to share socio-cultural characteristics with their clients which might contribute to their effectiveness (Foreit et al., 1992; Martin, 1995). It has also been reported that CBD agents provide an opportunity for women to get family planning services at home, thus, make savings on travelling costs, one of the major hindrances to access health services (Gerstl et al., 2001) as well as gaining time for other important activities (Koenig et al., 1997; Arends-Kuenning, 2001). People from Mavovo village had more access to contraceptives from CBD agents compared to Kidundui and Gombero villages perhaps because of the distance to the health facilities. Whereas, in Mavovo village people had to walk for more than $5 \mathrm{~km}$ to the nearest health facility, those in the other two villages travelled less than $5 \mathrm{~km}$.

Despite the family planning policy guidelines stipulating that services should be offered for free in public facilities, nearly two thirds of the clients reported to have paid for the services. About a quarter of those getting services from CBD agents also reported to have paid. Anecdotal reports quoted from some respondents claim to have paid about US $\$ 0.10$ for syringes. However, this information was refuted by the service providers who reported that injectables were always brought with special syringes for the purpose. Apparently, even some of the clients in the poorer category reported to have paid for the services at the health facilities or to the CBD agents. Due to low wages in low income countries, some government employed health staffs have been reported soliciting informal payments from patients (Rowe et al., 2005; Roenen et al., 1997). The potential advantage that CBD agents have, in reaching the poorer, are likely to be undermined if such payments will continue unabated. In addition to contradicting the national policy guidelines such payments might deny access to potential users especially the poorer. There is need for further research to establish the nature of payments and the influencing factors. By understanding the dynamics involved, programmes might identify solutions to the problem or explore the possibilities to make the payments official, if found affordable by clients.

This study has shown that people in the rural settings of Muheza district were able to access information and contraceptives from CBD agents and health facilities, regardless of their wealth status. However, payments solicited for services are likely to deter people in need from accessing the services. There is need to address the issue of informal payments by creating formal mechanisms of remunerating or providing incentives to CBD agents.

This study used community-led wealth ranking criteria for categorizing people into the various wealth statuses. This could undermine the validity of the results as well as limit generalizability of the study findings. Asset index has normally been used to categorize respondents according to their relative socio-economic status (Gillepsie et al., 2007). However, the narrow range of variation in wealth status in rural settings require 
alternative methods for measuring wealth status otherwise, the chance of observing a difference if at all exists is reduced. For example, in this study, when analysis of wealth status was done using housing standard as a criterion (TDHS, 2005), over $80 \%$ of the people fell under the poorer category and only $5 \%$ had houses that were rated as less poor. Moreover, findings from this study need to be interpreted with caution given the descriptive cross-sectional design employed.

\section{Acknowledgements}

We wish to acknowledge the contribution of Lucy Ikamba for the logistic arrangements and supervisory work. This study was funded by the Tanzania German Programme to Support Health (TGPSH/GTZ).

\section{References}

Arends-Kuenning, M. (2001) How do family planning workers' visits affect women's contraceptive behaviour in Bangladesh? Demography 38, 481-496.

Bertrand, J. (1995) Access, quality of care and medical barriers in family planning programmes. International Journal of Family Planning Perspectives 21, 64-74.

Foreit. J., Garate, M. \& Brazzoduro, A. (1992) A comparison of the performance of male and female CBD distributors in Peru. Studies in Family Planning 23, 58-62.

Gerstl, S., Amsalu, R. \& Ritmeijer, K. (2006) Accessibility of diagnostic and treatment centres for visceral leishmaniasis in Gedaref State, northern Sudan. Tropical Medicine and International Health 2, 167-175.

Gillepsie, D., Ahmed, S., Tsui, A. \& Radloff, S. (2007) Unwanted fertility among the poor: an inequity? Bulletin of the World Health Organization 85, 100-107.

Jacobs, B. \& Price, N. (2005) Improving access for the poorest to public sector health services: insights from Kirivong operational health district in Cambodia. Health Policy and Planning 21, 27-39.

Jahanfar, S., Ghodsi, M., Shahpoorian, F. \& Jamshidi, R. (2005) Community-based distribution and contraceptive usage in Iran. Journal of Family Planning and Reproductive Health Care 31, 194-197.

Janowitz, B., Chege, J., Thompson, A., Rutenberg, N. \& Homan, R. (2000) Community based distribution in Tanzania: costs and impacts of alternative strategies to improve worker performance. International Family Planning Perspectives 26, 158-160; 193-195.

Koenig, M., Hossain, M. \& Whitaker, M. (1997) The influence of quality of care upon contraceptive use in rural Bangladesh. Studies in Family Planning 28, 278-89.

Martin, T. (1995) Women's education and fertility: results from 26 demographic and health surveys. Studies in Family Planning 26, 187-202.

TDHS (2005) Tanzania Demographic and Health Survey 2004-05. National Bureau of Statistics, Tanzania and ORC-Macro, Dar es Salaam, Tanzania

National-Bureau-of-Statistics. (1999) Tanzania Reproductive and Child Health Survey. (1999) Tanzania National Bureau of Statistics and Measure DHS. ORC Macro. Calverton, Maryland, USA.

Prata, N., Vahidnia, F., Potts, M. \& Dries-Daffner, I. (2005) Revisiting community-based distribution programs: are they still needed? Contraception 72, 402-407. 
Roenen, C., Ferrinho, P., Van Dormael, M., Conceicao, M. \& Van Lerberghe, W. (1997) How African doctors make ends meet: an exploration. Tropical Medicine $\mathcal{E}$ International Health 2, 127-135.

Routh, S., Ashraf, A. \& Stoeckel, J. (2001) Consequences of the shift from domiciliary distribution to site-based family planning services in Bangladesh. International Family Planning Perspectives 27, 82-89.

Routh, S., Thwin, A. \& Baqui, H. (1997) Cost-effectiveness and sustainability aspects of MCH-FP programmes in Bangladesh: a review of the past and present programmes. ICDDR(B). Dhaka. Bangladesh.

Rowe, A., de Savigny, D., Lanata, C. \& Victoria, C. (2005) How can we achieve and maintain high-quality performance of health workers in low-resource settings? Lancet 366, 1026-1035.

Shah, I. \& Chandra-Mouli, V. (2007) Inequity and unwanted fertility in developing countries. Bulletin of the World Health Organization 85, 86-87.

Thang, N. \& Anh, D. (2002) Accessibility and use of contraceptives in Vietnam. International Family Planning Perspectives 28, 214-219. 